\title{
Improving vaccination uptake with the implementation of an immunisation Nurse Practitioner
}

\section{AUTHORS}

SONJA ELIA MAdvNursPrac, RN ${ }^{1}$

KIRSTEN PERRETT MBBS, FRACP, PhD 1,2

FIONA NEWALL PhD, MN, B.Sci(Nsg), RN ${ }^{3,4}$

\section{CORRESPONDING AUTHOR}

SONJA ELIA Immunisation Service, Department of General Medicine, Royal Children's Hospital 50 Flemington Rd, Parkville, Victoria 3052, Australia
1. Immunisation Service, Department of General Medicine, Royal Children's Hospital Parkville, Victoria 3052, Australia

2. Vaccine and Immunisation Research Group (VIRGo), Murdoch Children's Research Institute and Melbourne School of Population and Global Health, The University of Melbourne, Victoria 3010, Australia.

3. Department of Nursing and Department of Paediatrics, The University of Melbourne, Victoria 3010, Australia

4. Nursing Research Department, Royal Children's Hospital, Parkville, Victoria 3052, Australia

\section{ABSTRACT}

Patients at increased risk of vaccine preventable diseases require additional vaccines that are not licensed for Nurse Immunisers to administer without a prescription. An Immunisation Nurse Practitioner (NP) at the Royal Children's Hospital (RCH) Melbourne was introduced to address deficiencies in the current management of these patients. NP endorsement requires successful completion of a Masters level study program, plus the equivalent of three years $(5,000)$ hours full-time experience in advanced clinical nursing. The Immunisation NP was endorsed in May 2017 and since then, the Immunisation service at RCH has recorded a 140\% increase in uptake of Meningococcal $B$ vaccine as well as improved delivery of immunisations to special-risk patients. In addition, there was improved access to specialist immunisation advice as well as improved opportunistic immunisation of inpatients. New initiatives were implemented including immunisation of needle phobic patients using nitrous oxide sedation. This paper describes the outcomes of employing an Immunisation NP at the $\mathrm{RCH}$, Melbourne.
What is currently known about the topic?

- Nurse Practitioners provide excellent, patientcentred care whilst also contributing to research, education, leadership and management.

- There is much literature on describing Nurse Practitioner specialty roles however, none in the area of Immunisation.

What this paper adds:

- A Nurse Practitioner (NP) role in the specialty field of immunisation can contribute to improving hospital inpatient rates of immunisation, facilitate uptake of non-scheduled vaccines and decrease pressure on wait times for a specialist clinic appointment.

- The Immunisation NP reflects the full diversity of nursing practice and addresses the many service gaps in the previous delivery model, that can be emulated by paediatric nurses in other specialist areas.

Key Words: immunisation, nurse practitioner, hospital, vaccine 


\section{INTRODUCTION}

Vaccinations have reduced morbidity and mortality from a multitude of infectious diseases and are one of the most effective public health interventions to date. ${ }^{1}$ In Victoria, Australia, accredited nurse immunisers deliver approximately $23 \%$ of vaccinations in local government/ council clinics, whilst $65 \%$ of vaccinations are administered in general practice (this includes by practice nurses). ${ }^{2}$ Nurses have the knowledge, time and skills to help families make informed decisions about vaccinations and can strengthen adherence with immunisation schedules.3 "Fully immunised" coverage rates in Australia are $94.3 \%$ at 12 months of age, and $94.5 \%$ at 60 months of age. ${ }^{2}$

The role of the Nurse Practitioner (NP) can improve access to health services and offer diversity and flexibility in service provision. This paper is aimed at describing the Immunisation NP role at the Royal Children's Hospital (RCH), Melbourne.

\section{SETTING}

The RCH, a tertiary children's hospital established the first dedicated Immunisation Service in Australia, with support from the Department of Health - Immunisation Section, Victoria. Established in 2001, the RCH Immunisation Service, including a Drop-in centre, provides opportunistic vaccines to patients and visitors as well as expert clinical advice, predominantly provided by the nursing staff. This can be challenging, particularly with the introduction of new vaccines, increasing complexities of the National Immunisation Program and Australian mandatory vaccination policies. These policies require children to be fully vaccinated, on a catch-up schedule or medically exempt from vaccination in order to receive certain governmentsubsidised family assistance payments ('No jab, No pay') or access childcare and/or kindergarten ('No jab, No play’).

\section{CLINICAL SERVICE ACTIVITY}

There has been a steady increase in the number of consumers attending the Drop-in Centre over the past 13 years (Figure 1). The Nurse Practitioner role was implemented in May 2017 and there has been a significant growth in activity from July 2017 onwards.

\section{NEEDS ANALYSIS LEADING TO THE INTRODUCTION OF A NP-MODEL}

An NP is a registered nurse educated and authorised to function autonomously and collaboratively in an advanced and extended clinical role. 4 The rationale for implementing an Immunisation NP role was the gap in the existing immunisation service delivery model, primarily in the provision of vaccines outside the scope of the accredited nurse immuniser.

As of March 2021, there were 501 Nurse Practitioners endorsed in Victoria, which represents $23 \%$ of NP's in Australia. ${ }^{5}$

However, there are only six endorsed Immunisation NP's in Australia, with three in Victoria, two in Queensland and one in South Australia. This is significant, as nurses are considered pivotal to the success of immunisation programs, because their knowledge is sought after, and they invest a substantial amount of time with families. ${ }^{6}$

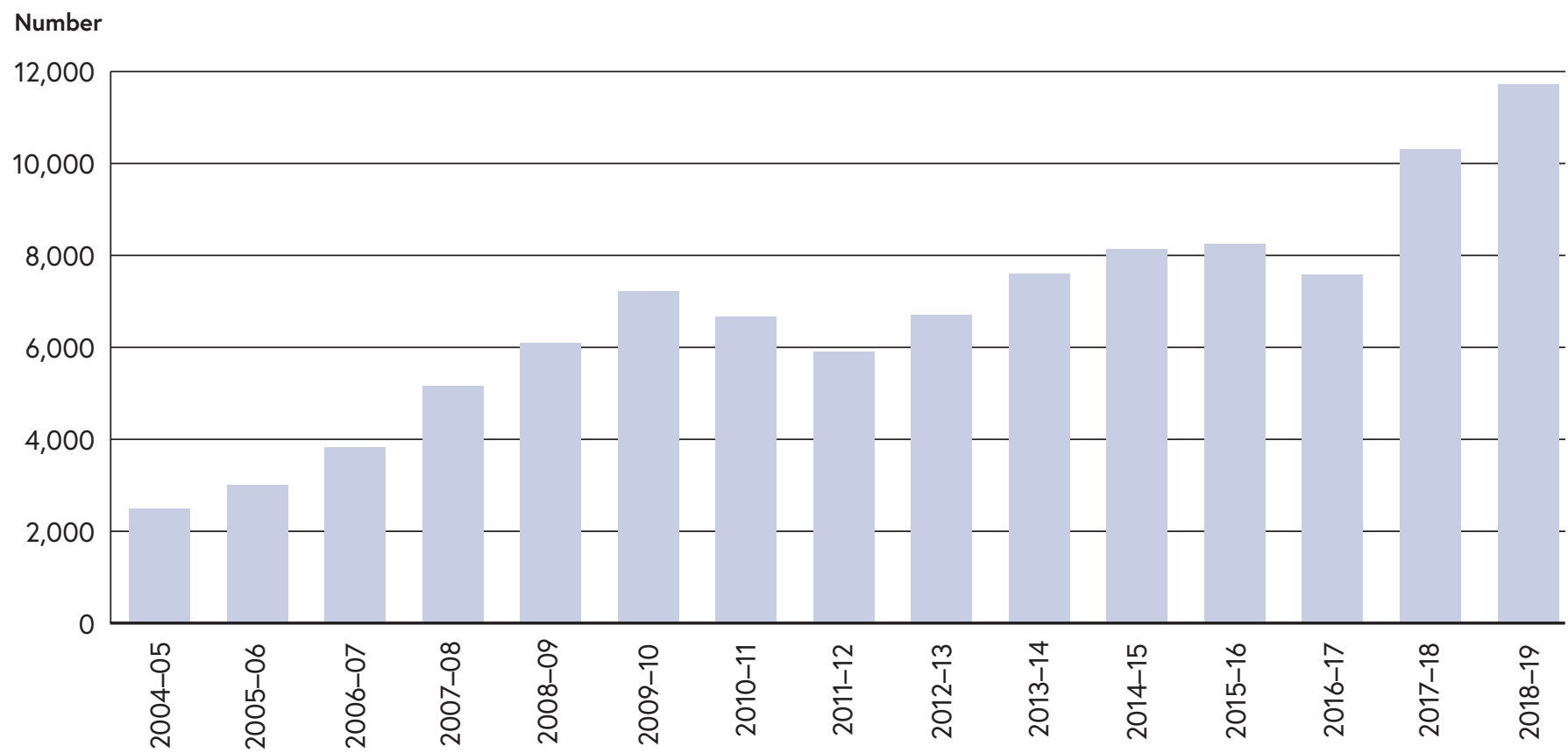


It was identified that significant gaps in the immunisation service model at the RCH existed. First, vaccine hesitancy (people who delay or refuse vaccines) was a growing challenge for immunisation providers. These families were referred to the specialist outpatient clinic for discussion with an immunisation paediatrician. Vaccine hesitancy referrals to this clinic were increasing, reflected in a study by Forbes and colleagues which described that $28 \%$ of referrals to the specialist immunisation clinic were for vaccine hesitancy and $10 \%$ of these patients failed to attend. ${ }^{7}$

Second, special risk patients (Table 1 ) often required an outpatient clinic appointment to discuss individualised vaccination plans with an immunisation paediatrician. These complex patients require serology as well as additional vaccines not on the National Immunisation Program (NIP) or licensed for Nurse Immunisers to administer without a prescription. At times there were significant delays in getting an immunisation outpatient clinic appointment, (four weeks for a new/review appointment) which had the potential to either delay live vaccines or immunosuppressive treatment until the appointment date.

TABLE 1: ADDITIONAL VACCINES NOT ON THE NATIONAL IMMUNISATION PROGRAM (NIP) OFTEN REQUIRED BY SPECIAL RISK PATIENTS

\begin{tabular}{|l|l|}
\hline Vaccine & Indication for use \\
\hline Meningococcal ACWY & $\begin{array}{l}\text { Solid Organ Transplant Recipient (SOTR) } \\
\text { Inflammatory Bowel Disease (IBD) }\end{array}$ \\
\hline Meningococcal B & $\begin{array}{l}\text { SOTR } \\
\text { Oncology } \\
\text { IBD } \\
\text { Aboriginal and Torres Strait Islander }\end{array}$ \\
\hline $\begin{array}{l}\text { Hepatitis A and B } \\
\text { combined }\end{array}$ & $\begin{array}{l}\text { SOTR } \\
\text { IBD }\end{array}$ \\
\hline Hepatitis A & $\begin{array}{l}\text { SOTR } \\
\text { Cystic Fibrosis } \\
\text { IBD }\end{array}$ \\
\hline
\end{tabular}

Nurse Immunisers are approved under regulation 8(1) and regulation 161 of the Drugs, Poisons and Controlled Substances Regulations 2017 to administer specified vaccines. ${ }^{8}$ Patients who attend the Drop-in centre for vaccination often required vaccines that were not on this list (Table 1). These vaccines require orders in the Electronic Medical Record (EMR) to be completed by the Immunisation paediatricians including a prescription to collect the vaccine from the hospital pharmacy. This was not time-efficient given the Immunisation paediatrician's were not always hospital based or busy with other roles.

\section{SERVICE DELIVERY BENEFITS OF AN IMMUNISATION NP}

In 2017, a Victorian nurse became the third in Australia to attain endorsement as an NP in the field of immunisation, working in the RCH Immunisation service. Since implementing the Immunisation NP in the Drop-in Centre, the wait times for the outpatient clinic reduced from four weeks to one to two weeks (a 50\% reduction). In the first six months, the Immunisation NP also consulted 44 patients in the outpatient setting alongside the medical staff and attended post-clinic meetings to discuss the patients and their plans of care.

In terms of prescribing rights, the NP directly prescribed vaccines in the EMR allowing ward based Registered Nurses to administer the vaccines. This could be done by a prescriber within the treating team, however a previous study has shown that during admission, one quarter of inpatients are not up-to-date with routine scheduled immunisations and $42 \%$ of those inpatients were opportunistically vaccinated. ${ }^{9}$ Since the employment of the NP role, the number of inpatients opportunistically immunised has improved to $57 \%$, an increase of $15 \%$.

In 2016, 283 Meningococcal B vaccines were administered to special risk patients. In 2017, the year of NP endorsement, the numbers increased to 697 and in 2018, 683 doses administered. Whilst there may be other contributing factors to this increase, e.g. improved parental awareness, this vaccine requires a prescription to allow it to be administered. This increase of $140 \%$ in two years, demonstrates that access to this important vaccine by the most vulnerable patients at $\mathrm{RCH}$ is being achieved. Similarly, Hepatitis A/B vaccine uptake for transplant recipients and other immunosuppressed patients has increased by $50 \%$ in the two years.

An area not anticipated to be a point of difference with the role introduction, was immunisations under sedation via the Drop-in Centre. From 2012-2016, the Immunisation service offered immunisations under sedation for paediatric patients with anxiety disorders, needle phobia, developmental or behavioural disorders in the RCH Day Medical Unit (DMU). ${ }^{10}$ This involved an appointment in the specialist outpatient clinic, and then a subsequent booking in DMU. With the Immunisation NP having the ability to prescribe nitrous oxide, medical gases were installed in the Drop-in Centre and from 01/08/2018-31/01/2020, 113 patients were successfully immunised at the time of first presentation, decreasing overall number of visits.

The NP role not only benefitted patients and families, but had the added advantage of improving revenue. With 81 sedation admissions in the first 12 month period, this generated over \$138,ooo in Weighted Inlier Equivalent Separation (WIES) activity based funding. In 2018, a total of 973 doses of Meningococcal vaccine were administered, with 290 of these for parents wishing to purchase the vaccine, as it is not on the NIP and their child was not in a special risk group. This enabled the Immunisation service to generate revenue of over $\$ 8,000$ from vaccine sales in 12 months.

There are limited findings regarding the economic impact of NP's, and difficulty in comparing NP costs and health 
care costs. ${ }^{11}$ However, it is important for NPs to demonstrate financial benefits with the implementation of the role in order to ensure sustainability.

There is much discussion in the literature about NP relationships within the multidisciplinary team and collaboration. ${ }^{12,13}$ The Immunisation NP role was developed in conjunction with the Immunisation Paediatricians and nursing staff. Regular meetings were established to determine Clinical Practice Guidelines as well as the medication formulary, and this provided the opportunity for key stakeholders to discuss and define the NP role. This is crucial to effective collaborative care, as described in the qualitative study by Hurlock and colleagues. ${ }^{12}$

\section{CHALLENGES}

It was anticipated that there may be issues impacting the implementation of the Immunisation NP, particularly the relationship of the NP with the other Immunisation nurses. Burgess \& Purkis identified that team members are often unprepared to welcome and support the new NP role. ${ }^{14}$ Considering the small team, the NP needed to communicate effectively, involving them in decision making and maintaining clinical visibility. This not only ensured the success of the role, but has now motivated others to consider NP endorsement in the field of immunisation.

A mentoring partnership, in which NPs are supported to manage concerns and challenges is vital in role development. ${ }^{14}$ The Immunisation NP was provided with an appropriate medical mentor as well as networking opportunities with other NPs from the organisation. The Immunisation paediatricians are the direct mentors to the $\mathrm{NP}$ and role model the style of consultation in a way that demonstrates collaboration not competition.

Challenges with implementation of the role that have not been successfully resolved includes backfilling the NP position during periods of leave. This has resulted in decreased Meningococcal B vaccine delivery as well as no booked admissions for immunisation under sedation during these periods.

\section{CONCLUSION}

In Australia, there are very few Nurse Practitioners in the field of immunisation and this is not unique to specialty areas of nursing. Since the introduction of the NP role there has been improved hospital inpatient rates of immunisation, enhanced uptake of non-scheduled vaccines and decreased pressure on wait times for a specialist clinic appointment. Additional benefits, such as the sedation service were identified, demonstrating that the role has further enhanced the excellent service provided to $\mathrm{RCH}$ patients and the wider community. It is anticipated that advanced practice nurses will pursue the NP role if the need is identified in their area of practice where clear objectives and potential benefits are explored.
Acknowledgements: The authors thank the Immunisation service nursing and medical staff at the Royal Children's Hospital, Melbourne, Australia for their support and mentorship of the Immunisation Nurse Practitioner. Thanks also to Ms Bernadette Twomey, Executive Director of Nursing and Ms Danielle Smith, Director of Ambulatory Services for their support and guidance with implementation of the role.

\section{REFERENCES}

1. Orenstein WA, Ahmed R. Simply put: vaccination saves lives. Proc Natl Acad Sci. 2017; 114(16): 4031-33.

2. Hull B, Hendry A, Dey A, Brotherton J, Macartney K, Beard F. Annual Immunisation Coverage Report, 2017. National Centre for Immunisation Research and Surveillance. Sydney. 2017. Available from: http://www.ncirs.org.au/reports

3. Hoekstra S, Margolis L. The importance of the nursing role in parental vaccine decision making. Clin Pediatr. 2016; 55(5): 401-3.

4. Nursing and Midwifery Board of Australia. Registration Standard: Endorsement as a Nurse Practitioner. Nursing and Midwifery Board of Australia. 2016. Available from: https://www.nursingmidwiferyboard.gov.au/RegistrationStandards/Endorsement-as-a-nurse-practitioner.aspx

5. Nursing and Midwifery Board of Australia. Registrant data. Nursing and Midwifery Board of Australia. 2020. Available from: https://www.nursingmidwiferyboard.gov.au/about/statistics. aspx

6. Desmond N, Grant C, Goddyear-Smith F, Turner N, PetousisHarris $\mathrm{H}$. Nurses make a difference in immunisation service delivery. Aust J Adv Nurs. 2011; 28(4): 28-35

7. Forbes TA, McMinn A, Crawford N, Leask J, Danchin M. Vaccination uptake by vaccine-hesitant parents attending a specialist immunisation clinic in Australia. Hum Vaccin Immunother. 2015; 11(12): 2895-903.

8. Department of Health and Human Services. Nurse Immunisers. Department of Health and Human Services. 2020. Available from: https://www2.health.vic.gov.au/public-health/ immunisation/immunisers-in-victoria/nurse-immunisers

9. Elia S, Perrett K, Newall F. Providing opportunistic immunisations for at-risk inpatients in a tertiary paediatric hospital. J Spec Pediatr Nurs. 2017; 22: e12167. Available from: https://doi.org/10.1111/jspn.12167

10. Cheng DR, Elia S, Perrett KP. Immunisations under sedation at a paediatric hospital in Melbourne, Australia from 2012-2016. Vaccine. 2018; 36(25): 3681-85.

11. Naylor MD, Kurtzman ET. The role of Nurse Practitioners in reinventing primary care. Health Aff. 2010; 29(5): 893-99.

12. Hurlock-Chorostecki C, Van Soeren M, MacMillan K, Sidani S, Donald F, Reeves S. A qualitative study of nurse practitioner promotion of interprofessional care across institutional settings: perspectives from different healthcare professionals. Int J Nurs Sci. 2016; 3(1): 3-10.

13. McDonnell A, Goodwin E, Kennedy F, Hawley F, Gerrish K, Smith C. An evaluation of the implementation of Advanced Nurse Practitioner (ANP) roles in an acute hospital setting. J Adv Nurs. 2014; 71(4): 789-99.

14. Burgess J, Purkis ME. The power and politics of collaboration in nurse practitioner role development. Nurs Inq. 2010; 17(4): 297-308. 